\title{
Ozone in the treatment of musculoskeletal infections
}

\author{
Srikanth Sundaresh \\ Consultant Orthopaedic Surgeon and PhD Research Scholar. India.
}

\section{ABSTRACT}

\section{OPEN ACCESS}

\section{Citation}

Sundaresh S. Ozone in the treatment of musculoskeletal infections [abstract].

Proceedings of the 5Th WFOT Meeting; 2016 Nov 18-20; Mumbai, India. J Ozone Ther. 2018;2(2). doi: 10.7203/jo3t.

2.2.2018.11149

\section{Academic Editor}

Jose Baeza-Noci,

School of Medicine, Valencia

University, SPAIN

\section{Editor}

World Federation of Ozone

Therapy, Bolgna, ITALY

\section{Received}

December 9, 2017

\section{Accepted}

December 10, 2017

Published

March 4, 2018

\section{Intellectual Property}

Srikanth Sundaresh. This is an open access article distributed under the terms of the Creative Commons Attribution License (CC BY 4.0), which permits unrestricted use, distribution, and reproduction in any medium, provided the original author and source are credited.
Ozone, an antibacterial, has a spectrum of action which is bigger than any antibiotic known today. Very few bacteria can resist the onslaught of ozone and this is again dependent on the route of delivery of the ozone- oxygen mixture. Musculoskeletal infections, mainly chronic osteomyelitis and foot ulcers, were taken as criteria for study. Chronic osteomyelitis of the long bones, mainly the tibia was preferred as route of entry into the marrow cavity is easier.Foot ulcers, diabetic or trophic were selected on random basis. Graphic representation based on dimension and pictures taken on regular intervals were the criteria for evidence of healing. All cases were subjected to a short course of antibiotics, based on culture and sensitivity reports, and ozone was added as an adjuvant to see whether ozone hastens recovery and if yes, the quality of recovery, the reduction in financial burden and the requirement of surgery like skin grafts or amputations. All cases were treated using ozone bagging and rectal insufflations on alternate days. It was concluded that ozone not only hastens the healing process, provides antibacterial remedy, but also ensures the healing occurs with good granulation tissue and without the requirement of a skin graft.

Keywords: Ozone, foot ulcers, chronic osteomyelitis, ozone bagging, rectal insufflations.

\section{Author Information}

docsri77@gmail.com 